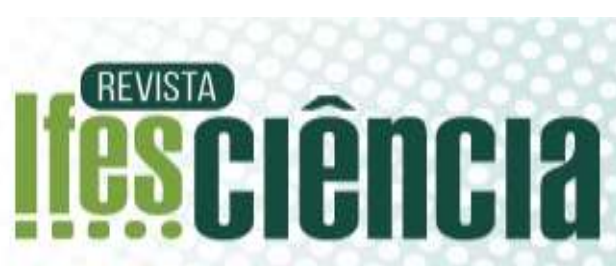

\section{"POEMOPATIA": A CADA DIA, GOTAS DE POESIA...}

\author{
“POEMOPATIA": EVERYDAY DROPS OF POETRY
}

\author{
Sandra Regina Selino ${ }^{1 *}$ \\ Dra. Sandra Mara Mendes da Silva Bassani² \\ ${ }^{1}$ Instituto Federal do Espírito Santo. E-mail: srselino@ hotmail.com.br \\ ${ }^{2}$ Instituto Federal do Espírito Santo. E-mail: sbassani@ifes.edu.br \\ *Autor para correspondência.
}

Artigo submetido em 05/03/2019, aceito em 15/08/2019 e publicado em 20/12/2019

Resumo: Despertar o gosto pela leitura e pela escrita tem sido um grande desafio para os professores. Essa tarefa se torna mais complicada quando o trabalho com textos literários tem apenas cunho moralizante, ou quando os livros adotados pelas escolas são escritos por quem não escreve exclusivamente para crianças e jovens, com uma produção, normalmente, para fins mercadológicos. Reconhecendo a importância do texto poético em sala de aula, este estudo aponta suas contribuições, quando este não é utilizado como pretexto para lições de cunho moral e didatismo. O artigo "Poemopatia" (LIMA, 1997) e a obra É isso ali, de José Paulo Paes (1993), serviram de base para a elaboração de um projeto de leitura que foi realizado em uma turma de $1^{\circ}$ ano do Ensino fundamental, de uma escola da Rede Pública de Ensino no interior do estado do Espírito Santo. Os resultados obtidos com a realização desse projeto, mostraram que, ao ser despida de utilidade, a poesia é capaz de provocar o leitor e sensibilizá-lo a ponto de passar a gostar de ler e ter mais intimidade com seu idioma, como aconteceu com aos alunos envolvidos.

Palavras-chave: Literatura infantojuvenil; poesia; humor; leitor.

Abstract: Awakening a taste for reading and writing has been a major challenge for teachers. This task becomes more complicated when the work with literary texts is only moralizing, or when the books adopted by schools are written by those who do not write exclusively for children and young people, with a production, usually for marketing purposes. Recognizing the importance of the poetic text in the classroom, this study points to its contributions when it is not used as a pretext for moral lessons and didacticism. The article "Poemopatia" (LIMA, 1997) and the work "É isso ali", by José Paulo Paes (1993), served as the basis for the elaboration of a reading project that was carried out in a 1st-grade elementary school class. of the Public Education System in the state of Espírito Santo. The results obtained with the realization of this project showed that being stripped of utility, poetry is able to provoke the reader and sensitize them to the point of enjoying reading and having more intimacy with their language, as happened to the students involved.

Keywords: Children's and Teenage Literature. Poetry. Humor. Reader.

\section{INTRODUÇÃO}

O presente artigo tem por objetivo trazer reflexões sobre as contribuições do texto poético na formação do leitor e a importância da leitura de poesia por prazer, sem se preocupar com a didatização. Por meio da análise do artigo "Poemopatia", 
produzido por Lima (1997), e da obra de Paes (1993), nos propusemos a falar sobre a importância do trabalho com texto poético na infância e sobre o humor na poesia infantojuvenil, aspecto responsável por atrair pequenos leitores. Para atingir nosso objetivo, faremos breve exposição sobre a literatura para crianças na segunda seção. Na terceira seção apresentaremos o artigo de Lima (1997) que nos motivou para a escolha do título de nosso trabalho. $\mathrm{Na}$ quarta seção, com base no artigo "Poesia e humor para crianças", de Cunha (2005), falaremos sobre as formas de humor presentes no livro É isso ali (1993) de José Paulo Paes; todavia para nossa análise usaremos sete poemas. Na quinta seção traremos um relato de experiência que corrobora com a ideia de que a poesia é diversão, encantamento e pode contribuir para despertar o gosto pela leitura e pela escrita, ideia presente também na conclusão deste trabalho.

\section{UM POUCO DE TEORIA}

A produção de uma literatura voltada para o público infantojuvenil tem suscitado diferentes questionamentos, que vão desde a conceituação do termo à questão mercadológica. Sabemos que há grande marketing por trás de determinados títulos publicados, mas acreditamos que ainda há produções que não veem o leitor infantojuvenil como mero consumidor de "[...] uma literatura para ser ouvida e acatada (não para fazer falar) [...]" (GOLDIN, 2012, p. 59).

No artigo, "A invenção da criança: divagações em torno da literatura infantil e da infância", Goldin (2012) traz uma reflexão interessante sobre ler e escrever antes e depois de Babel, referindo-se à história da Torre de Babel presente no livro de Gênesis. Falar de uma literatura para criança, segundo ele, é um objeto de difícil conceituação, e que também é preciso considerar que o que hoje parece óbvio, o acesso dos pequenos à leitura e à escrita, nem sempre foi assim, "[...] durante séculos, ler era privilégio de poucos, entre os quais não figuravam as crianças nem as mulheres" (GOLDIN, 2012, p. 59). Mas, com o decorrer dos anos, o acesso à leitura e à escrita mudou o cenário da produção literária, tendo em vista a evolução da literatura para criança, que tem buscado de diversas formas o diálogo e a participação ativa das crianças no mundo.

Para o autor, desde que foi inventada, a palavra escrita vem cobrando maior relevância nas práticas sociais, e ao utilizá-la de mil maneiras diferentes temos transformado o sentido de atividades como ler e escrever.
A linguagem não é somente um instrumento de comunicação: é uma fonte de mal-entendidos, de ambivalências, de obscuridades e de equívocos. Não há palavras, não há frase e, portanto, não há textos que possam ser entendidos da mesma forma por todos e por cada um dos falantes de uma língua em particular [...] há uma Babel no interior de cada idioma. A palavra é o lugar onde é encenada uma disputa contínua e oculta entre nossas diferentes avaliações de mundo, uma luta para interpretar e criar a realidade e participar dela. (GOLDIN, 2012, p. 54).

Considerando as ambivalências e mal-entendidos presentes na língua, o autor discorre sobre o valor da escrita, o poder transformador da leitura e outros questionamentos que envolvem a história da infância e a história da literatura para crianças. Goldin apresenta a ideia de Philippe Ariès de que há poucos séculos é que se começa a tratar e compreender a criança como um ser diferente do adulto.

\footnotetext{
A produção literária para crianças cresce a cada dia e há um interesse maior em fomentar a leitura entre os pequenos. Sem dúvida, ao fazê-lo, avançamos em relação a um nivelamento de poderes, a um equilíbrio maior de direitos e responsabilidades entre adultos e crianças (GOLDIN, 2012, p. 85).
} 
O autor também salienta que: "Não há nada mais desagradável que um adulto que desdenha as crianças, nem tão tolo quanto alguém que acredita que o diálogo com elas implica se dobrar a seu nível intelectual ou a de seu discurso" (GOLDIN, 2012, p. 86).

Coadunando com as ideias apresentadas pelo referido autor, abordamos neste trabalho a importância da literatura infantojuvenil nas salas de aula quando não vem carregada de intenções e de valores. Não queremos nos deter ao fato de que falta muito para a literatura ter o devido lugar na comunidade escolar, pois o que vemos, quando vemos, é a utilização de livros que chegam às escolas distribuídos por meio de políticas governamentais e que são trabalhados, muitas vezes, de modo a não contribuir para a formação do leitor crítico. A escola foi promovida à grande compradora de livros, sem filtro crítico para identificar uma obra como sendo de qualidade (ANDRUETTO, 2012).

Queremos refletir sobre a leitura de textos, como diz Cândido (1995) em "O direito à literatura", cuja experiência não é inofensiva. A leitura que nos inquieta, nos diverte, nos torna mais críticos; para isso é preciso que o livro não se revista de funcionalidade.

Todavia, precisamos ser criteriosos para não incorremos na didatização do texto literário, e em vez de contribuir para despertar o gosto pela leitura de livros literários, promovamos o efeito contrário. Em um tempo em que tudo precisa ter uma utilidade prática, talvez seja o momento de deixar que a palavra literária nos atinja.

Para quem é sensível, é no corpo que a palavra em delírio, qual bactéria, encontra sua morada. Não se trata da palavra que porta ideias moralizantes nem de algo que sirva de modelo para a escrita que "funciona" em nossos tempos, tampouco de algo que tenha qualquer tipo de utilidade para a vida prática. A palavra literária nos atinge como puro gozo, por isso deve marcar sua diferença em um mundo em que toda e qualquer coisa precisa estar revestida de utilidade (CARVALHO, 2014, p. 81).

Em se tratando de literatura para crianças e jovens, de acordo com Andruetto (2012), bom seria se o campo da literatura infantojuvenil não tivesse proprietários, mas inquilinos, visitantes e viajantes, gente que simplesmente escrevesse e em cuja escrita por vezes assomasse algum escrito que pudesse ser lido por leitores crianças ou jovens.

Carvalho (2014) fala da importância de o professor insistir em “[...] práticas de leitura que não sejam o desvendamento de todos os sentidos, mas a reduplicação do instante de não entendimento" (p. 83).

O gosto pela leitura deve invocar, inclusive, o "desgosto". Um bom ponto de partida é se perguntar por que determinados livros nos parecem tão desagradáveis, tão estranhos. A estranheza geralmente faz parte do projeto de escrita e deve, por isso, ser considerada no momento da leitura. Ninguém é obrigado a gostar desse tipo de livro, mas, durante a formação do leitor, tomar conhecimentos de textos convulsos, que estão à beira do precipício (lembramos os livros de Raduan Nassar, Clarice Lispector e Lúcio Cardoso, entre outros), contribui para o salto dos livros de aventura para os, digamos, reflexivos. Um dos objetivos, ao ler um texto "estranho", é, inclusive, não camuflar esse estranhamento. Ao escolher trabalhar com esse tipo de texto, o professor não pode naturalizar o espanto dos alunos, fingindo que ele mesmo não se espanta (CARVALHO, 2014, p. 101).

O texto literário satisfaz necessidades básicas do ser humano, e é capaz de enriquecer a percepção e a visão de mundo das pessoas: "Negar a fruição da literatura é mutilar a nossa humanidade" (CANDIDO, 1995, p. 122).

Acreditarmos que a fruição da literatura não deve ser negada e que o texto literário direcionado ao público infantil, 
com seu arranjo especial da linguagem, por sua riqueza, deve ser apresentado desde cedo às crianças. No próximo capítulo abordaremos o texto poético como sendo o que mais se aproxima da criança pela sua linguagem especial que explora as figuras de linguagem de efeitos sonoros e até visuais, capazes de despertar e aguçar a sensibilidade do leitor infantojuvenil.

\section{POEMOPATIA: DOSES DE POESIA?}

O termo Poemopatia foi retirado do artigo de Lima (1997) conforme apresentamos no início deste trabalho. Para que possamos entendê-lo melhor, falaremos um pouco dessa produção que ousadamente sugere a poesia como um remédio que, segundo a autora, é um tratamento que deveria ser receitado a todos, principalmente para as crianças.

Ancorando-se no haicai de Angela Leite de Souza, "Mil vezes ao dia/ três gostas de poesia. Uso interno somente", Lima (1997), de um modo bem peculiar, brinca e parodia a estrutura de uma bula de remédio ao apresentar uma visão poemopática para o texto poético. Começando pelo título "Informações ao (im) paciente leitor", a autora faz uso das seguintes partes de uma bula: indicações, contraindicações, reações adversas, posologia e superdosagem.

Um poema encerra em sua composição ingredientes básicos, ativos, que são elaborados sob a forma de palavras. Essas, em diferentes momentos, farão brotar substâncias pertencentes ao grupo dos fabricadores de versos. Esse grupo, que geralmente se encontra em constante atividade, consegue resultados eficazes, pois a arte de poetar age favoravelmente prevenindo ou provocando possíveis comportamentos nos diversos leitores. A poesia é feita de propriedades e potências aproximadamente iguais às da própria natureza (LIMA, 1997, p. 124).
Ao falar sobre a questão da faixa etária, Lima apresenta a ideia de que os poemas podem e devem ser lidos "[...] tanto por gente pequena e gente média como por gente grande. $\mathrm{O}$ adulto que não se diverte em ser, de vez em quando, criança ou jovem novamente, é um chato" . Entendemos que a poesia infantojuvenil a todo tempo surpreende o leitor, seja ele criança, jovem ou adulto; poemas como os de Paes (1993), por exemplo, trazem à tona $\mathrm{o}$ riso pelas surpresas contidas nos jogos de palavras que utiliza.

No capítulo "Indicações", a autora aborda a questão da didatização do texto literário e utiliza a expressão " [...] formas degenerativas de leituras anteriores e que tenham deixado sequelas" (LIMA, 1997, p. 126) para os casos em que se tenham usado o poema para retirar todos os verbos no presente do indicativo, (devo aqui admitir que, em vários momentos de minha vida profissional, fiz uso dessa metodologia). Como tratamento para possíveis sequelas, recomenda um poema hipnótico, no caso o de Manoel Bandeira.
A ONDA DÁ
A ONDA DÁ
A ONDA DÁ
A ONDA DÁ
A ONDA DÁ
A ONDA DÁ
ONDINHAS
Bandeira (2014)

Quanto ao uso do tratamento poemopático, Lima diz serem desconhecidas "contraindicações" e que todos podem fazer uso da poesia. Em resposta aos que dizem que certos poemas não devem ser dados à criança, a autora cita Lajolo (1988) que afirma que o ponto de encontro entre o poeta e a criança, na poesia infantil contemporânea, ocorre ou pela tematização do cotidiano infantil ou

\footnotetext{
${ }^{1}$ A autora justifica sua ideia com o poema de José Paulo Paes presente na obra $E$ isso ali, sobre a qual falaremos posteriormente.
} 
pela adoção de algum ponto de vista compartilhado pelos pequenos leitores.

Segundo Lima, parece ser complicado e inaceitável unir a criança a determinados temas, como poemas lúgubres. Tudo tem limite, mas "[...] se o leitor não for alérgico à plurissignificação que cerca um poema, não há nada que o contraindique. A poesia se encarrega de tudo" (LIMA, 1997, p. 129).

Quanto a essa apresentação da criança a determinados temas, Bordini (1986, p. 8) expõe o fato de que "Simular para as crianças mundos talhados pelas insatisfações adultas, desde que esteticamente eficientes e nivelados às suas possibilidades de entendimento, pode ser proveitoso: a criança deseja também a verdade, além do jogo".

Um poema em que podemos verificar um pouco de verdade além do jogo é o de Murilo Mendes (1955, p. 56):

Mamãe vestida de rendas
Tocava piano no caos
Uma noite abriu as asas
Cansada de tanto som,
Equilibrou-se no azul,
De tonta não mais olhou
Pra mim, pra ninguém!
Cai no álbum de retratos

Mendes (1955)

Falar sobre a morte com crianças parece um tema muito forte, mas a maneira sugerida pelo poeta fica mais perto à compreensão do leitor infantil.

Quanto às reações adversas para o uso de poemas, a autora afirma que em alguns podem ocorrer reações mais intensas. Alguns sentirão uma necessidade intensa de comentar, criticar, expor de alguma forma, oral ou escrita, o poema lido. São experiências proporcionadas pela leitura e escrita que serão compartilhadas.

Na seção Posologia, Lima parodia a tão repetida frase "Não tome medicação sem o conhecimento de seu médico", para: "Tome poesia sem o conhecimento de seu médico, pois não será perigoso para a saúde" (LIMA, 1997, p. 131). Acreditamos que um dos perigos que pode vir a acontecer é o usuário querer tornar-se poeta e, assim, como já dizia Drummond (2008), esse usuário pode dar inúmeras idas e vindas no reino das palavras em busca de encontrar os poemas que esperam ser escritos.

Tecendo comentários sobre o ensaio de Candido (1995), O direito à literatura, Lima (1997, p. 131) diz que "Se a literatura é um direito humano, o poema, talvez, seja o tipo de texto literário que dever estar mais próximo da criança, pois a sua linguagem é fácil de ser digerida", e sugere "[...] uma colher de sopa da poesia de Leo Cunha, logo pela manhã" (p. 132).

\section{Atrás do arco-íris, quem for, Periga encontrar um baú Cheinho de lápis de cor. Cunha (1997)}

Prosseguindo com sua "bula", ao se referir à "Superdosagem: sinais e sintomas", a autora afirma que a overdose de poesia pode apresentar efeitos múltiplos, nenhum preocupante, todavia é bom que se apresente o principal sintoma que é percebido na fala do indivíduo, pois ela alcança um alto grau de perfeição funcional, logo, o progresso do indivíduo tende a provocar espanto, uma vez que passa a ter mais liberdade política e adquire uma visão crítica de tudo que o cerca. "É melhor refletir bastante antes de se render ao magnetismo da poesia. Uma vez dentro dela (ou ela dentro do homem), a transgressão estará realizada e 'olhar livre' diante do mundo, referido por Oswald de Andrade, se fará permanente" (LIMA, 1997, p. 135).

Considerando a ideia apresentada por Mário Quintana de que "[...] quem faz um poema abre uma janela", acreditamos que a criança deve ser a primeira a se debruçar sobre essa janela, uma vez que não há "contraindicações".

A partir de agora, faremos menção a alguns textos da obra É isso Ali, de Paes

\footnotetext{
${ }^{2}$ Texto retirado do site:

https://www.escritas.org/pt/t/37684/quem-faz-umpoema-abre
} 
(1993), autor que demonstrou entender o universo infantil e respeitá-lo em suas produções. $\mathrm{O}$ aspecto dessa produção que daremos ênfase é o humor. Da mesma forma que Leo Cunha (2005) em Poesia e humor para crianças, analisaremos três maninfestações do humor, tendo em vista que pode apresentar-se de formas diversas. Humor no jogo de palavras, humor no jogo de ideias e humor na invenção do cotidiano são as formas que abordaremos.

\section{POESIA E HUMOR: BRINCANDO COM AS PALAVRAS}

O livro de poemas infantojuvenil $E$ isso ali (1993) de José Paulo Paes, é uma obra que, no início da carreira de professora alfabetizadora, caiu de paraquedas em minhas mãos. Na biblioteca da escola em que lecionava, estava à procura de alguns títulos para serem apresentados aos alunos, uma turma de $1^{\text {a }}$ série $^{3}$. Queria levar textos poéticos, pois acreditava possuírem uma linguagem mais acessível e que nos permitiriam momentos prazerosos. Não tinha outro objetivo a não ser ter um momento de leitura e, quem sabe, a partir de algumas falas dos alunos, fazermos algumas observações.

Meus olhos pousaram na obra de José Paulo Paes. A princípio fiquei chocada com a ilustração da capa: a figura de um Frankenstein verde-limão, com cabelos azuis, óculos de sol e de roupa preta. Como, na ocasião, estava com pouco tempo, peguei o livro e deixei para analisálo em casa. Qual o conteúdo de um livro que trazia semelhante ilustração? Hoje, não consigo entender por que agi de modo tão preconceituoso em relação à obra.

O exemplar que levei para casa fazia parte da $11^{\mathrm{a}}$ impressão da Editora Salamandra. Foi paixão "à primeira lida", se é que posso usar essa expressão. Devorei a obra em poucos minutos e não a larguei mais. Passou a morar em minha bolsa. Todos os dias a levava para escola e lia um poema para a turma em que lecionava.

\footnotetext{
${ }^{3}$ Em 2004 ainda não vigorava a nomenclatura "Anos iniciais do Ensino Fundamental".
}

É fazendo uso desse livro que passaremos a falar sobre o humor, característica marcante de José Paulo Paes, para isso tomaremos por base as leituras realizadas na disciplina de Literatura Infantojuvenil $^{4}$ que compõe a grade curricular do Mestrado Profissional em Letras-Profletras.

Em nossas leituras tivemos a oportunidade de conhecer a produção de diferentes autores, entre eles o que nos chamou a atenção foi o texto de Cunha (2005), que aborda poesia e humor direcionados às crianças. Para o autor, muito se valoriza a poesia infantil marcada pelo lirismo, como os textos de Cecília Meireles, Roseana Murray e outros que trazem como semelhanças na produção o "[...] lirismo, delicadeza, expressividade, frequentemente um olhar reflexivo $\mathrm{e}$ filosófico sobre o ser humano, a natureza e as coisas do mundo" (CUNHA, 2005, p. 79). O autor afirma não ter nada contra os "poetas poéticos", que seguem essa linha poética, inclusive, muitas vezes se inclui nesse grupo, todavia, pretende destacar a importância da outra corrente, que é menos valorizada do que deveria.

\begin{abstract}
Ela existe em contraste com a primeira, mas não necessariamente em oposição a ela - tanto que diversos poetas transitam entre as duas. Esta segunda tendência tende a se afastar da visão predominante sobre o que é o texto poético. Tratase de uma poesia menos lírica, menos séria, menos "profunda". Talvez seja exatamente por isso que, por mais que seja apreciada por crianças e adultos, poucas vezes ela é nivelada ao primeiro grupo (CUNHA, 2005, p. 80).
\end{abstract}

Poesia mais voltada para o lúdico do que para o lírico é o que encontramos na produção de José Paulo Paes. Conforme citado, abordaremos o humor que se apresenta em três formas: no jogo das palavras, no jogo das ideias e na reinvenção do cotidiano. Para tanto,

\footnotetext{
${ }^{4}$ A professora responsável por essa disciplina foi a Dra. Letícia Queiroz de Carvalho.
} 
selecionamos alguns poemas que exemplificarão cada uma dessas formas.

O livro $E$ isso ali, publicado em 1984, foi a primeira obra de Paes, que trabalhou por muito tempo na indústria química até se decidir pela literatura, e isso só aconteceu depois dos anos 80, segundo consta em sua biografia escrita por Silva (2007).

\section{a) O humor no jogo das palavras}

Para o poeta, "poesia é brincar com palavras" como se brinca com outros brinquedos infantis, mas a diferença é que as palavras ficam mais novas à medida que são usadas, o mesmo não acontece com "bola, papagaio, pião".

De acordo com Paes, brincar com as palavras é uma atividade natural, não é preciso o uso de vocabulários rebuscados, muito menos se preocupar com a didatização do texto poético.

O humor, de acordo com Carmen Surrallés (2000) apud Cunha (2005, p. 82), "[...] se alimenta das 'bobagens', das descrições hiperbólicas e das palavras que atraem pela sonoridade", e consegue dar conta das necessidades físicas e psicológicas das crianças.

No poema abaixo, observa-se um pouco desse humor que se alimenta de "bobagens":

\section{VIDA DE SAPO \\ O sapo cai \\ num buraco \\ e sai. \\ Mas noutro buraco \\ cai. \\ O sapo cai}

num buraco

É um buraco

a vida do sapo.

A vida do sapo

é um buraco.

\section{Buraco pra cá.}

Buraco pra lá.

Tanto buraco enche o sapo.

Paes (1993).

A poesia de Paes se alimenta de coisas simples que acontecem no dia a dia e que nem sempre as notamos, como, por exemplo, o pular de um sapo, que apresentado por meio do jogo de palavras, explorando a sonoridade, de modo concreto explora os espaços, o vazio do papel em branco, sugere no último verso ou esconde a intenção de trazer à memória a frase popular "encher o saco".

Muitas interpretações podem advir desse poema, como sugestão de que ele seja metalinguístico, a vida cíclica do sapo de cair e sair do buraco, de passar por momentos de sufoco e conseguir sair deles, pode se referir à vida do poeta; todavia, não é o objetivo deste trabalho uma análise mais detalhista.

Quanto ao humor em "Vida de sapo", é possível verificar sua presença quando "O poeta investe na graça que surge da sonoridade melodiosa, ou inusitada das palavras" (CUNHA 2005, p. 83). As rimas (cai/sai), as repetições (buraco/sapo) são alguns dos recursos utilizados para fazer com que o poema pareça uma brincadeira de criança, como as parlendas ou trava-línguas.

Como já mencionamos, o poeta não tem por objetivo transmitir valores, percebe-se que sua busca é, antes de tudo, pelo movimento da linguagem, “[...] por uma poesia simples tal qual são as crianças que apenas se contentam em ser, e nesse ser se divertem, se recriam, se expressam como seres únicos que são, como poemas" (SILVA, 2007, p. 69).

b) $\mathrm{O}$ humor no jogo das ideias

Considerando que o "humor pode nascer também da brincadeira com ideias e conceitos, e não exatamente com as palavras" (CUNHA, 2005, p. 84), Paes soube muito bem criar poemas que 
parodiam ditos populares, provérbios, cantigas de rodas e outros textos que circulam socialmente.

\section{ACIDENTE}

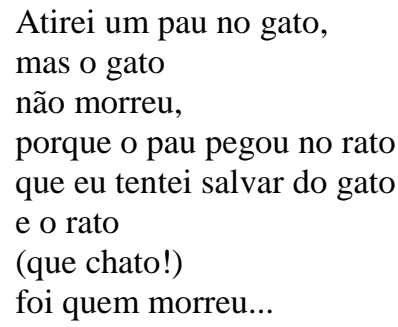

Paes (1993).

Parece-nos ser raridade encontrar uma criança, em idade escolar ou não, que desconheça a cantiga de roda "Atirei o pau no gato". Mais uma vez é possível identificar o humor, desta vez no campo das ideias. Ao fazer uso da intertextualidade, recurso recorrente na obra do autor, identificamos o humor por meio de um final inusitado.

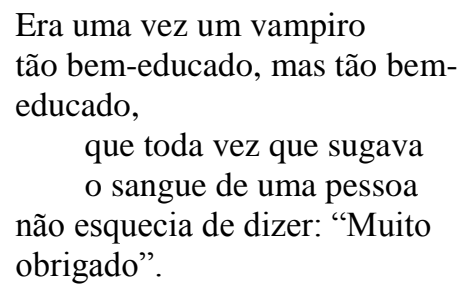

Paes (1993).

De acordo com Silva (2007), José Paulo Paes sempre destacou a importância de chamar a atenção da criança para a fruição lúdica da forma e do sentido do poema, e que não devia deixar a escola usar a poesia como simples auxiliar no ensino de noções de gramática. Acreditamos, assim como muitos que nos antecederam na abordagem sobre a literatura infantojuvenil, que o importante é fazer do contato com a poesia fonte de prazer gratuito e não de obrigações escolares.

c) O humor na reinvenção do cotidiano

Deixar o humor aflorar por meio das situações mais banais que a criança encontra em seu cotidiano é uma das características do Paes, inclusive, em depoimentos, ele fez referência à novidade perene da vida nas pequenas/grandes coisas:

Manuel Bandeira e Carlos
Drummond de Andrade me
ensinaram que a poesia é a
redescoberta da novidade perene da
vida nas pequenas/grandes coisas do
dia a dia. Desde então, em maior ou
menor grau, venho tentando ser fiel,
em quanto escrevo, a essas duas
últimas concepções. Meu ideal
poético é a desafetação, a concisão e
a intensidade postas todas a serviço
da minha própria visão de mundo
(PAES, 2003, apud SIILVA, 2007,
p.101).

Em meio ao trivial, à surpresa, à invenção, elementos próprios do universo infantil, o poeta "[...] procura enxergar uma situação como uma criança faria (o que é um pouco diferente de "voltar a ser criança') e extrai daí o humor" (CUNHA, 2005, p. 87).

\section{MISTÉRIOS DO PASSADO \\ Quando Cabral o descobriu, Será que o Brasil sentiu frio?}

Diz a História que os índios comeram o bispo Sardinha.

Mas como foi que eles conseguiram abrir a latinha?

Qual o mais velho, diga num segundo:

D. Pedro I ou D. Pedro II?

De que cor era mesmo (eu nunca decoro)

o cavalo branco de Marechal Deodoro?

Paes (1993).

Brincar com as palavras nem sempre é uma brincadeira inofensiva, ingênua, o que podemos verificar nos dois primeiros versos do poema Mistérios do passado. Para Cunha (2005, p. 88):

Não custa lembrar que uma das maiores armas do humor é apresentar, 
por trás da despretensão e da irreverência, uma visão crítica, um olhar de estranhamento, uma nova forma de pensar o mundo e revelar seus absurdos, suas contradições, suas injustiças.

Não reduzir a poesia aos estudos gramaticais e, a partir do referencial infantil, transmitir algo novo com um novo sabor para as crianças fez parte da trajetória de Paes, que, por meio de reflexões feitas de forma lúdica, inseria a crítica ao mundo real dentro do próprio brincar reinventando o cotidiano.

\section{FICÇÃO CIENTÍFICA}

Depois de uma viagem
pelo espaço sideral,
o astronauta chegou ao seu destino
final:
Um planeta diferente
cujo em-cima estava em-baixo
e o atrás ficava na frente.
Um planeta tão estranho
que a sujeira era limpa
e a água tomava banho.
Um planeta mesmo louco
onde o muito era nada
e o tudo muito pouco.
Um planeta dos mais raros:
o seu ouro era de graça,
o lixo custava caro.
O astronauta não gostou
e foi-se embora. Quando
pensou estar muito longe,
Viu-se outra vez chegando
num planeta onde, aliás,
o em-baixo ficava em-cima
e a frente estava por trás...

Paes (1993).

Em se tratando de humor, para Leo Cunha, mesmo o humor que parece se limitar à brincadeira ou aos jogos de linguagem, "[...] é capaz de despertar no leitor o gosto pelas palavras, o prazer de lidar de forma lúdica com os sons, os ritmos, e as formas das letras e palavras" (CUNHA, 2005, p. 88). Sendo assim, para exemplificar esse despertar no leitor o gosto pelas palavras é que passamos a relatar uma experiência pedagógica que se tornou inesquecível.

\section{INESQUECÍVEL É O QUE EXPERIMENTAMOS...}

A propósito, o título dessa seção faz parte de uma fala de Yunes (2002) e que neste momento reflete o que pretendo relatar: uma experiência inesquecível. "Inesquecível é o que experimentamos e reelaboramos como memórias das quais é possível tirar aprendizados, todos implicados com a afetividade. O que se aprende só de cabeça corre o risco de não tocar nossa vida e como tal torna-se estéril" (p.164).

Também quero fazer menção ao pensamento do filósofo Walter Benjamim (1987), quando diz que somos ricos quando temos experiências comunicáveis. Considero-me uma pessoa rica. $\mathrm{O}$ que passo a compartilhar é fruto de um trabalho desenvolvido em uma escola pública no interior do Espírito Santo, em uma cidade denominada Sooretama.

Conforme relatei, quando assumi uma turma de $1^{\text {a }}$ série decidi levar vários livros de poesia para a sala, mas sem a intenção de didatizá-los, queria apenas trabalhar a leitura pelo prazer e fruição. Ao cair-me às mãos, a obra de José Paulo Paes $E$ isso ali, egoisticamente assumi o controle do livro e não o devolvi mais à biblioteca. (Acabei de confessar um pecado que até então estava oculto). Durante muito tempo, procurei justificar tal atitude com: "Foi por uma justa causa". Pecado confessado, sigamos para o relato da experiência.

Foi no curso de Letras Português/Espanhol que me apresentaram ao artigo "Poemopatia", da professora Luciene Souza Lima. Logo me encantei com a ideia de usar a poesia como um tratamento. Esperei um momento em que pudesse elaborar o projeto e executá-lo. E foi quando terminei de ler o livro $E$ isso 
ali, que vi a possibilidade de colocar em prática o intento.

Ler poemas como forma de divertimento e prazer. Todos os dias iniciava a aula com um texto poético. Às vezes, começava a passar a atividade do dia sem ler um poema só para ver a reação das crianças. Todas reclamavam, queriam saber por que a aula estava diferente e eu, prazerosamente, pegava um livro da bolsa e começávamos a viajar. Cantávamos, encenávamos, divertíamos. A sala virava uma algazarra, alguns professores reclamavam da "indisciplina" da turma, mas a coordenadora pedagógica dava o seu aval para continuar o projeto.

Algumas vezes repetíamos um percurso que aprenderam a amar: viajar no "Trem de ferro" de Manuel Bandeira.

\section{TREM DE FERRO}

Café com pão
Café com pão
Café com pão
Virge Maria que foi isso maquinista?
Agora sim
Café com pão
Agora sim
Voa, fumaça
Corre, cerca
Ai seu foguista
Bota fogo
Na fornalha
Que eu preciso
Muita força
Muita força
Muita força [...]

Bandeira (2001)

Saíamos da sala e passeávamos pelos corredores recitando o poema. Todos em fila indiana, para o desconforto de outros professores. Foi conversando com a turma que decidimos que todas as crianças da escola também precisavam ter acesso aos poemas que nos encantavam todos os dias, logo, surgiu o nome do projeto: "Poemopatia: a cada dia gotas de poesia".

Fizemos uma seleção criteriosa, e muito difícil, pois os alunos não queriam deixar ninguém de fora, por exemplo Cecilia Meireles, Vinícius de Morais, José
Paulo Paes e outros nomes com os quais foram se familiarizando.

Coletamos caixas de remédios de todos os tamanhos. Os poemas selecionados foram digitados de modo a caberem nessas caixas que foram anexadas em diferentes locais da escola. Todo dia havia uma nova poesia. A alegria da turma era tamanha quando ficavam fiscalizando e viam que alguém parava para ler um poema: "Tia, tem alguém bebendo um poema!"

São lembranças de uma prática lá pelos idos de 2004, mas que até hoje me emocionam, principalmente por saber que, inexperiente que era, sem acesso às teorias que tenho hoje, consegui atingir de uma forma diferente aquelas crianças. Era gratificante ouvir dos gestores da escola que a turminha da $1^{\text {a }}$ série era muito questionadora, inteligente e volta e meia deixava escapar o que pensava sobre melhorias que deviam ocorrer na escola. Turminha que gostava de ler.

Como não podia ser diferente, os poemas de Paes (1993) eram os nossos favoritos.
INUTILIDADES
Ninguém coça as costas da cadeira. Ninguém chupa a manga da camisa. O piano jamais abana a cauda. Tem asa, porém não voa, a xícara.
De que serve o pé da mesa se não anda?
E a boca da calça se não fala nunca? Nem sempre o botão está na sua casa. O dente de alho não morde coisa alguma.
Ah! se trotassem os cavalos do motor ...
Ah! se fosse de circo o macaco do carro ...
Então a menina dos olhos comeria Até bolo esportivo e bala de revólver. Paes (1993).

A poesia, segundo Cunha (2005) deve ser, antes de mais nada, um espaço para o prazer, o encantamento com a palavra e a partir da palavra. Nisso também acreditamos. E foi assim: bebendo a cada 
dia gotas de poesias, que a turma da $1^{\mathrm{a}}$ série passou a ter o gosto pela leitura e escrita.

\section{CONCLUSÕES}

As reflexões e relatos apresentados neste trabalho refletem o que acreditamos quando o assunto é literatura infantojuvenil. Se podemos atribuir funções à poesia, uma delas é fazer a criança entrar em contato com seus sentimentos, com o prazer do jogo das palavras, incentivando-as a sentir as emoções através da linguagem. É a ludicidade a favor do despertar de mais um leitor que, provavelmente, passará a utilizar a linguagem com mais desenvoltura.

A apresentação da poesia como uma terapia, como sugere Lima (1997) em seu artigo, é muito válida e tive a oportunidade de comprovar seus efeitos. Os muitos jogos com as palavras tendem a aguçar a sensibilidade e o interesse dos leitores, um "efeito colateral" mais que desejável. Esse jogar com as palavras, conforme vimos nos poemas de José Paulo Paes, agradam não só ao público infantil, mas também ao adulto.

É preciso despir a poesia infantojuvenil da utilidade. A poesia não dever ser levada para o ambiente escolar como pretexto para discussões moralizantes durante as aulas. Lima conclui seu artigo citando um poema de Leo Cunha: "Gosto não se diz: curte". Parafraseando o autor, digo que: "Poesia não se discute, curte".

\section{AGRADECIMENTOS}

Agradecimentos à Dra. Letícia Queiroz de Carvalho por nos proporcionar diálogos maravilhosos nas aulas de Literatura Infanto-juvenil.

À FAPES pelo incentivo à pesquisa.

A professora Dra. Sandra Mara Mendes da Silva Bassani por aceitar o desafio de ser a minha orientadora e por ter contribuído para meu crescimento profissional e pessoal.

\section{REFERÊNCIAS}

ANDRADE, Carlos Drummond. Antologia poética. Rio de Janeiro: Record, 2008.

ANDRUETTO, Maria Teresa. Por uma literatura sem adjetivos. São Paulo: Pulo do Gato, 2012, p. 32-51.

BANDEIRA, M. Meus poemas preferidos. São Paulo: Global Editora, 2014.

BENJAMIN, Walter. - Obras escolhidas. Vol. 1. Magia e técnica, arte e política. Ensaios sobre literatura e história da cultura. Prefácio de Jeanne Marie Gagnebin. São Paulo: Brasiliense, 1987, p. 114-119.

BORDINI, Maria da Glória. Poesia Infantil. São Paulo: Ática, 1986, p. 8.

CÂNDIDO, Antônio. "O direito à Literatura". In: Vários escritos. São Paulo: Duas Cidades, 1995.

CARVALHO, Ana Maria Pessoa de. Ensino de língua portuguesa. São Paulo: Cengage Learning, 2014.

CUNHA, L. "Poesia e humor para crianças". In: OLIVEIRA, Ieda. O que é qualidade em Literatura Infantil e Juvenil? Com a palavra o escritor. São Paulo: DCL, 2005.

CUNHA, L. Debaixo de um tapete voador. Rio de Janeiro: Ediouro, 1997.

GOLDIN, Daniel. "A invenção da criança: divagações em torno da história da literatura infantil e da infância". In: Os dias e os livros. Divagações sobre a hospitalidade da leitura. São Paulo: Ed. Pulo do Gato, 2012. 
LIMA, Luciane Souza. "Poemopatia". In: RIBEIRO, Francisco Aurélio. Leitura e Literatura Infanto-juvenil. Vitória UFES- PPGL/CEE/DLLIMCB, 1997.

MENDES, Murilo. Poesias. Rio de Janeiro: José Olímpio, 1955, p. 56.

MEUS PRIMEIROS VERSOS Antologia de poetas brasileiros, v.4. Rio de Janeiro: Nova Fronteira, 2001.

PAES, José Paulo. É isso ali: poemas adulto-infanto-juvenis. Rio de Janeiro: Salamandra, 1993.

SILVA, Márcia Cristina. A criança e o poeta: José Paulo Paes e os seres em rotação. Dissertação (Mestrado) Universidade do Estado do Rio de Janeiro, Instituto das Letras, 2007.Disponível em http://www.posciencialit.letras.ufrj.br/imag es/Posciencialit/td/2007/14-marciacristina_ acrianca.pdf . Acesso em: 29/04/2018.

YUNES, Eliana. Leitura e socialidade: Literatura para crianças e velhos. In: SOUZA, Santinho Ferreira de. Olhares e perguntas sobre ler e escrever. Vitória: Flor e Cultura Editores, 2002. 